\title{
Robust Speed Control of an Induction Motor Drive using Wavelet-fuzzy based Self-tuning Multiresolution Controller
}

\author{
J.L Febin Daya \\ School of Electrical Engineering, VIT University - Chennai Campus \\ Chennai, India - 600127 \\ Email:febinresearch@gmail.com \\ V. Subbiah \\ Department of Electrical and Electronics Engineering, PSG College of Technology \\ Coimbatore, India - 641004 \\ Email:subbiah42@yahoo.com \\ P. Sanjeevikumar \\ School of Electrical Engineering, VIT University - Chennai Campus \\ Chennai, India - 600127 \\ Email:sanjeevi_12@yahoo.co.in \\ Received 7 March 2011; accepted 18 February 2013 \\ Abstract
}

\begin{abstract}
This paper presents a hybrid wavelet-fuzzy based multiresolution (MR) controller for robust speed control of induction motor. The discrete wavelet transform (DWT) is used to decompose the error between the actual speed and command speed of the induction motor drive in to different frequency components. A self-tuning fuzzy logic is used for online tuning of the controller parameters. The proposed controller has the ability of meeting the speed tracking requirements in the closed loop system. The complete indirect field oriented control scheme incorporating the proposed wavelet-fuzzy based MR controller is investigated theoretically and simulated under various dynamic operating conditions. Simulation results are compared with that of conventional PI controller and fuzzy based PI controller. The speed control scheme incorporating the proposed controller is implemented in real time using the digital processor (DSP) control board. Simulation and experimental results validates the effectiveness of the proposed controller over conventional controllers and proves to be more suitable for high performance applications.

Keywords: Wavelet-fuzzy, Induction Motor, Robustness, Indirect Field Oriented Control.
\end{abstract}

\section{Introduction}

The induction motor is one of the most widely used machines in industrial applications today due to its high reliability, simple construction, relatively low cost and modest maintenance requirements. Earlier, DC motors were extensively used in industries for variable speed and position control applications. The advantage is that the flux and the torque and be controlled easily as well as separately. However, DC motors have commutation problems. In order to overcome the drawback of DC motor, induction motors are preferred in industries. The field oriented control (FOC) technique made the dynamic behaviour of the induction motor similar to that of a separately excited DC motor. Hence they are now preferred for high performance applications. Though attractive, FOC methods suffer from disadvantages of sensitiveness to motor parameter variations such as the rotor time constant and incorrect flux measurement. 
With the advancements in power electronics and processor technology, digital control of induction drives using the field oriented approach has gained increasing popularity. The conventional speed controllers such as proportional- integral (PI) and proportional-integralderivative (PID) controller are used extensively for these applications. PI controller is very simple and is easy to implement. However, they exhibit significant steady state error and a long settling time when load disturbances are applied. The performance of the speed control system also depends on the accuracy of the slip calculation. Unfortunately, the slip calculation depends on the rotor time constant, which varies continuously according to the operational conditions. Thus the control parameters of PI controller are not adaptive.

Many solutions have been proposed to overcome the problems mentioned above, such as model reference adaptive control [3], sliding-mode control [2], variable structure control [12], self-tuning PI control [8] etc. Design techniques of all the above controllers depend on the exact mathematical model of the system. However, it is often difficult to develop an accurate system mathematical model due to unknown load variations, unknown and unavoidable parameter variations like saturation, temperature variations, and system disturbances.

In the past decade, intensive research has been done on the design and implementation of fuzzy logic controller (FLC), neural network controller (NNC) and hybrid controller for high performance applications of induction motor drives. The FLC is the simplest of all the intelligent controllers for induction motor speed control applications. However, FLCs have difficulties in determining appropriate control laws and tuning the parameters of the membership function according to the changes in the system. NNCs on the other hand, have the capability to adapt itself to changes in the control environment using the system input and output. It does not require complicated control theories and exact model of the system. However, NNC synthesis requires design of the control structure which includes selecting the neural network structure, weight coefficients and activation function. The selection of neural structure as the initial step is done by trial and error method, since there is no proper procedure for this. The complexity of the selected neural network structure is a compromise between the high quality of control robustness and the possibility of control algorithm calculation in real time. Hybrid controllers like neuro fuzzy controller implements high level learning and low computation power of neural network to fuzzy control system. However, the problem of finding a well defined procedure for finding the optimum network topology for induction motor drives still remains as a challenge.

Recent literature has reported works on the use of time frequency localization of wavelet transform in the speed control of electric drives. Wavelet transform has the ability to decompose wide band signals in to time and frequency localized sub bands. Wai et.al [11] have presented a wavelet neural network (WNN) based control system for an indirect field-oriented IM drive to track the reference speed input with adaptive learning rate. They have also presented a back stepping WNN for indirect field- oriented induction motor drive [4]. Hasan et al. [19] have developed different controllers for dc motors based on Wavelet network. Literatures also report the application of wavelet neural for online identification of Stator resistance of induction motor [16]. Pravez et al. [5] have carried out works on wavelet based PID controller for brushless dc servo motor speed control. Azadi et.al has developed a wavenet based control for vector control of PMSM drive [13]. The system lacks in its stability. Khan and Rahman [1], [10] have contributed tremendously in the field of wavelet based speed control. They have developed and implemented wavelet and WNN based multiresolution PID controller for the speed control of interior permanent magnet synchronous motor (IPSM) drive. But the problems associated with the wavelet neural controller are the complexity in the training of wavelet network, selection of appropriate architecture and the complexity in control algorithm.

Based on the above discussion it can be concluded that there is a recent trend in the research work on the application of wavelet transforms along with intelligent techniques such as neural network and fuzzy logic control for robust speed control of electric drives. Many works have been reported on combining the advantages of wavelet transform and neural network for the high performance applications of induction motor drives. However, very few simulation studies have been done on combining the advantages of wavelet transform and fuzzy logic for speed control of induction motor drives. 


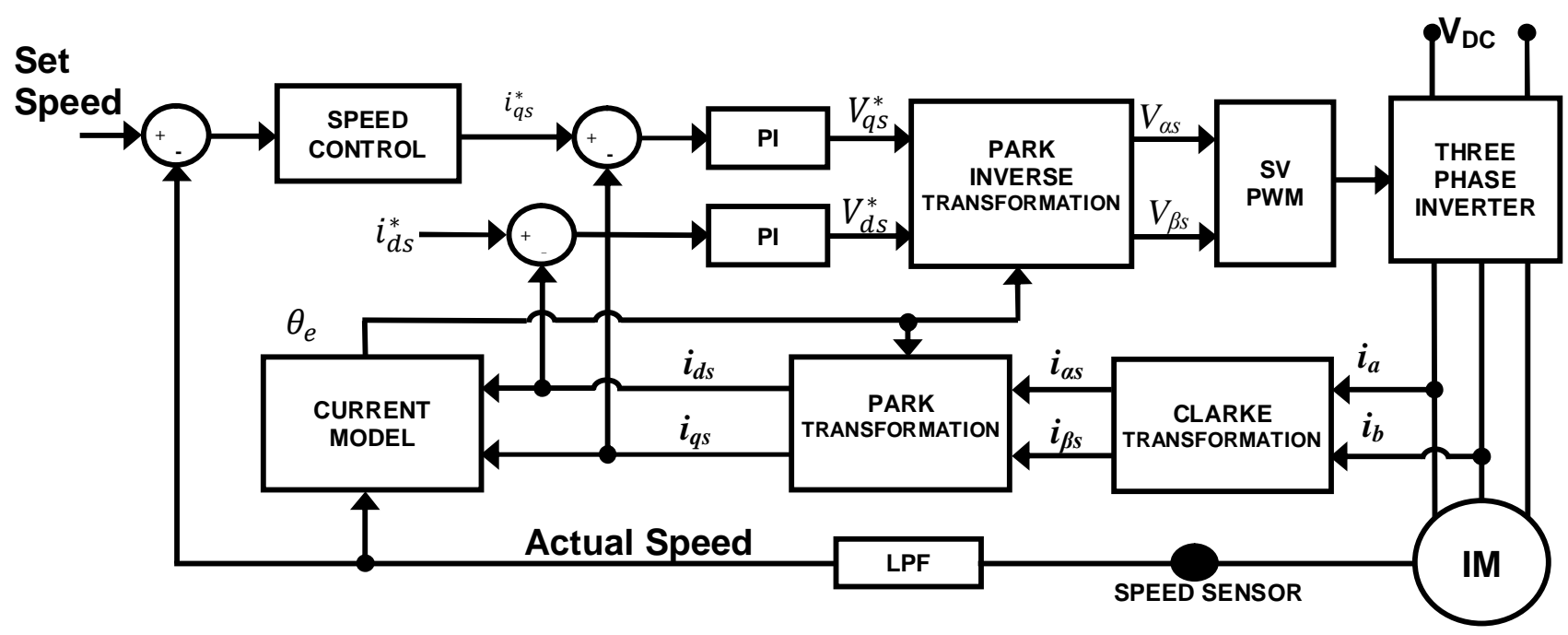

Fig. 1. Configration of an IFOC Induction motor drive with SVPWM

Therefore, an effort is aimed to develop a waveletfuzzy based controller for speed control of induction motor drives. This work presents a novel wavelet fuzzy based self-tuning multiresolution controller for robust speed control of indirect field oriented induction motor drive. The proposed control scheme has been evaluated through simulation and experimental results and is compared with conventional PID controller and fuzzy controller. The proposed controller is suitable for application, where the induction motor is operates in uncertain conditions and the prior information about the motor is limited. The proposed speed control scheme produced better robustness in terms of peak overshoot, settling time and lesser root mean square error (RSME).

\section{Induction Motor Drive Dynamics}

The configuration of speed control investigated in this paper is shown in Fig. 1. It applies IFOC to a three phase squirrel cage induction motor by means of a space vector pulse width modulation (SVPWM). The dynamic model of a three phase squirrel cage IM described by (1), is shown at the bottom of the page, in the $d^{e}-q^{e}$ synchronously rotating reference frame and by equation (2) - (4) as [7]

$$
\begin{gathered}
T_{e=} \frac{3}{2} \frac{P}{2} L_{m}\left(i_{q s}^{e} i_{d r}^{e}-i_{d s}^{e} i_{q r}^{e}\right) \\
T_{e}=J_{m} \frac{d \omega_{r}}{d t}+B_{m} \omega_{r}+T_{L}
\end{gathered}
$$

$$
\frac{d \theta_{r}}{d t}=\omega_{r}
$$

where $V_{d s}^{e}$ and $V_{q s}^{e}$ are the $\mathrm{d}$ axis and $\mathrm{q}$ axis stator voltages, $i_{d s}^{e}$ and $i_{q s}^{e}$ are the $\mathrm{d}$ axis and $\mathrm{q}$ axis stator currents, $i_{d r}^{e}$ and $i_{q r}^{e}$ are the $\mathrm{d}$ axis and $\mathrm{q}$ axis rotor currents, $R_{s}$ is the stator resistance per phase, $R_{r}$ is the rotor resistance per phase, $L_{s}$ is the self inductance of the stator, $L_{r}$ is the self inductance of the rotor, $L_{m}$ is the mutual or magnetizing inductance, $\omega_{e}$ is the speed of the rotating magnetic field, $\omega_{r}$ is the rotor speed, $P$ is the number of poles, $T_{e}$ is the electromagnetic torque developed, $T_{L}$ is the load torque, $J_{m}$ is the rotor inertia, $B_{m}$ is the rotor damping coefficient, and $\theta_{r}$ is the rotor position.

The $\mathrm{d}$ and $\mathrm{q}$ axis stator voltage is related to the three phase stator voltage by the following equation:

$\left[\begin{array}{l}V_{q s}^{e} \\ V_{d s}^{e}\end{array}\right]=\left[\begin{array}{cc}-\sin \omega_{e} t & \cos \omega_{e} t \\ \cos \omega_{e} t & \sin \omega_{e} t\end{array}\right]\left[\begin{array}{ccc}\frac{2}{3} & -\frac{1}{3} & -\frac{1}{3} \\ 0 & \frac{1}{\sqrt{3}} & \frac{1}{\sqrt{3}}\end{array}\right]\left[\begin{array}{l}V_{a s} \\ V_{b s} \\ V_{c s}\end{array}\right]$

Similarly the $\mathrm{d}$ and $\mathrm{q}$ axis stator current is related to the three phase stator current by the following equation:

$$
\left[\begin{array}{l}
i_{q s}^{e} \\
i_{d s}^{e}
\end{array}\right]=\left[\begin{array}{cc}
-\sin \omega_{e} t & \cos \omega_{e} t \\
\cos \omega_{e} t & \sin \omega_{e} t
\end{array}\right]\left[\begin{array}{ccc}
\frac{2}{3} & -\frac{1}{3} & -\frac{1}{3} \\
0 & \frac{1}{\sqrt{3}} & \frac{1}{\sqrt{3}}
\end{array}\right]\left[\begin{array}{l}
i_{a s} \\
i_{b s} \\
i_{c s}
\end{array}\right]
$$

The field-oriented control is achieved by making the magnetizing current at a constant rate by setting $i_{d r}^{e}=0$.

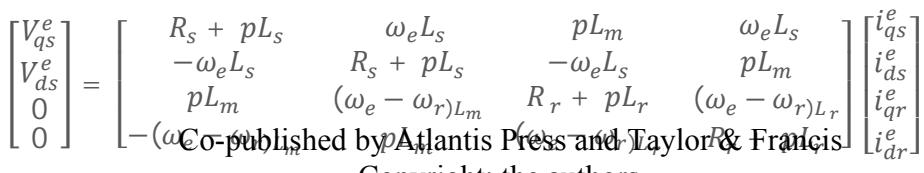


Using this assumption, the mathematical formulas can be written as:

$$
\begin{gathered}
\omega_{s l}=\frac{R_{r}}{L_{r}} \frac{i_{q s}^{e}}{i_{d s}^{e}} \\
i_{q s}^{e}=-\frac{L_{m}}{L_{r}} i_{q r}^{e} \\
T_{e}=\frac{3}{2} \frac{P}{2} \frac{L_{m}}{L_{r}} \lambda_{d r}^{e} i_{q s}^{e}
\end{gathered}
$$

where $\omega_{s l}$ is the slip speed and $\lambda_{d r}^{e}$ is the $\mathrm{d}$ axis rotor flux linkage. Given reference speed $\omega_{\text {ref }}$, the error signal is calculated, which is the difference between the reference speed and the actual speed sensed by the speed sensor. This error signal is processed by the speed controller to generate the torque-producing current component $i_{q s}^{*}$.

IFOC achieves ideal torque and flux decoupling by means of $\mathrm{d}-\mathrm{q}$ axis transformations and two proportional-integral (PI) controllers. The outputs of the PI controllers are applied to the inverse park's transform, the outputs of which are the stator voltages in orthogonal reference frame [9]. These voltages are used for generating the switching signals by the SVPWM, which drives the inverter to produce the actual voltage to be applied to the motor.

\section{Wavelet Based Multiresolution Analysis}

Wavelet transform is a powerful statistical tool which can be used for parsimonious representation of signal. It can be used to perform multiresolution analysis (MRA), which can extract and localize frequency components of a signal at a time. MRA represents a function as a successive limit of approximations, at different stages. Each stage consists of an approximate version and detail version. In general the discrete wavelet representation of a signal $f(t)$ is defined in terms of its orthonormal bases, that is scaling and wavelet function as [25]

$f(t)=\sum_{k} C_{N}, k \emptyset_{N}, k(t)+\sum_{m=1}^{N} \cdot \sum_{k} d_{m}, k \varphi_{m}, k(t)$

Where

$$
c_{m, k}=\sum_{k} f(t) \bar{\emptyset}_{m, k} k(t)
$$

$$
d_{m, k}=\sum_{k} f(t) \bar{\varphi}_{m, k}(t)
$$

where $\bar{\emptyset}(t)$ and $\bar{\varphi}(\mathrm{t})$ are conjugates of scaling function $\emptyset(t)$ and wavelet function $\varphi(t)$ respectively.

Discrete wavelet transform (DWT) is a time scale representation of a digital signal using digital filtering technique. It is performed through cascaded stages of high pass $(\mathrm{H})$ and low pass $(\mathrm{G})$ filters, followed by down sampling, which performs frequency dilation. The frequency sub bands $\mathrm{d}^{1}$ and $\mathrm{a}^{1}$ represents the detail and approximate co-efficient at first level of decomposition. The approximate co-efficient at first level of decomposition $a^{1}$ is further decomposed, after being by down sampled by two. This gives the second level of detail and approximate co-efficients, represented as $\mathrm{d}^{2}$ and $\mathrm{a}^{2}$. These are also called as frequency sub bands at level two.

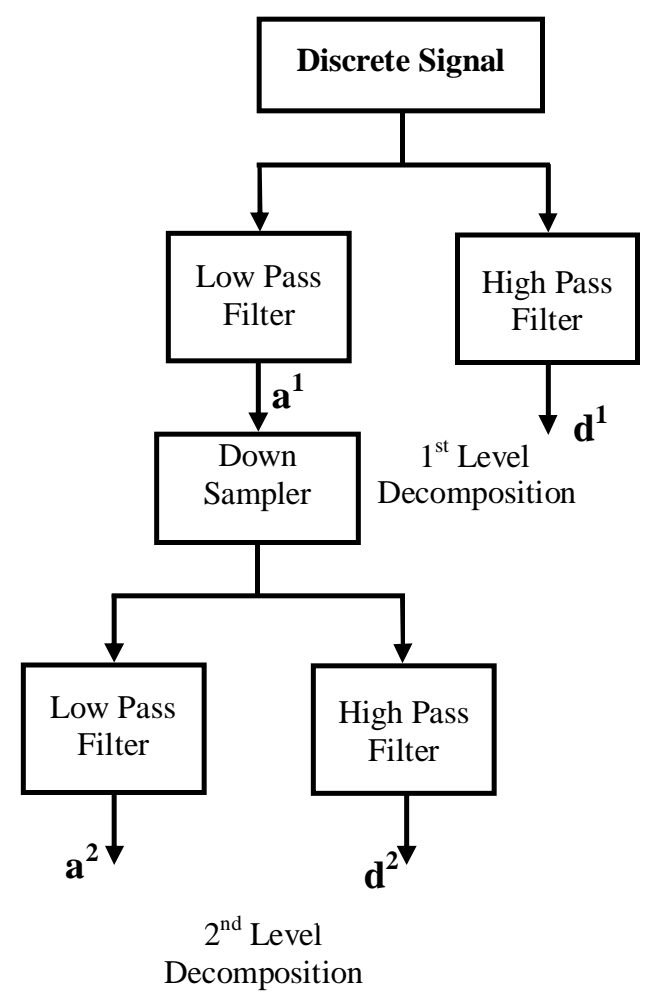

Fig. 2. DWT Decomposition Tree 
The co-efficient of first level and second level of decomposition, can be mathematically represented as

$$
\begin{aligned}
& d^{1}[n]=\sum_{k=0}^{N-1} x[k] h[n-k] \\
& a^{1}[n]=\sum_{k=0}^{N-1} x[k] g[n-k] \\
& d^{2}[n]=\sum_{k=0}^{N / 2-1} a^{1}[k] h[n-k] \\
& a^{2}[n]=\sum_{k=0}^{N / 2-1} a^{1}[k] g[n-k]
\end{aligned}
$$

where, $d^{1}[n], a^{1}[n]$ are the outputs of high pass and low pass filter at level one and $d^{2}[n], a^{2}[n]$ are the outputs of high pass and low pass filter at level two. The DWT decomposition tree is shown in Fig 2.
Before applying wavelet, it is required to select appropriate wavelet function and the number of levels of decomposition. Different methods are available in the literature, but the minimum description length (MDL) data criterion [24] best suits to select the optimum wavelet function and the number of levels of decomposition of the error signal. The MDL criterion is given as [24]

$$
\begin{array}{r}
M D L(k, n)=\min \left\{\frac{3}{2} k \log N+\frac{N}{2} \log \left\|\tilde{\alpha}_{n}-\alpha_{n}^{(k)}\right\|^{2}\right\} \\
0 \leq k \leq N ; 1 \leq n \leq M \quad(17)
\end{array}
$$

where $\mathrm{k}$ and $\mathrm{n}$ are the indices, $\tilde{\alpha}_{n}$ is the wavelet transformed coefficients of signal $f, \alpha_{n}^{(k)}$ is a vector with $k$ non zero elements. $\mathrm{N}$ and $\mathrm{M}$ represents the length of signal and the number of wavelet filters respectively. The selection of appropriate wavelet is a compromise between the wavelets with short widths which generates

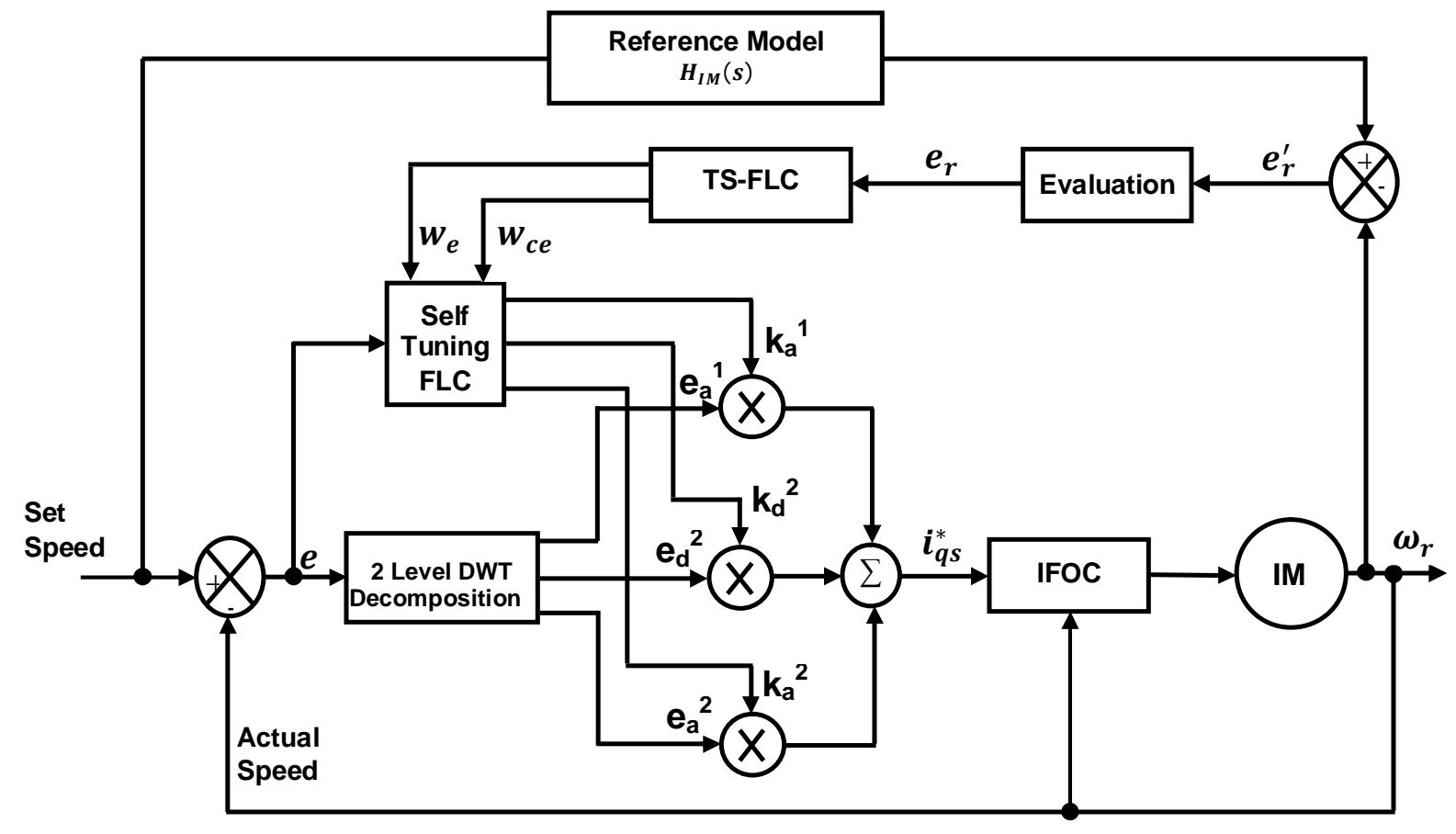

Fig. 3. Schematic of Wavelet Fuzzy based Speed Controller 
undesired noise and wavelets with larger width which localize the DWT coefficients. In the proposed method, all the wavelets which are available in the simulation tool are tested using the MDL criterion to select the best suitable wavelet. The "db4" wavelet which belongs to the orthogonal Daubechies family is chosen as the optimum one, for the proposed wavelet-fuzzy based control of induction motor drive.

\section{Wavelet based PID Controller}

In a conventional PID controller, the control output (u) is generated making use of the error signal (e) and further processing on it. The output of the PID controller is given by

$$
u=k_{p} e+k_{i} \int e d t+k_{d} \frac{d e}{d t}
$$

The gain constants $k_{p}, k_{i}$ and $k_{d}$ acts on the error, integral of error and derivative of error signal respectively as shown in (18). In terms of frequency, proportional and integral term corresponds to low frequency information and the derivative term corresponds to high frequency information of the given error signal.

Wavelet transform performs the same operation of decomposing a signal in to low frequency (detail) and high frequency (approximate) coefficients at different levels of resolution. This feature of the wavelet transform can be made use of in replacing the conventional PID controller for the expected control actions. The control signal for the wavelet based PID controller can be calculated from the detail and approximate coefficients of wavelet transform as [1]

$$
\begin{aligned}
u_{w}=k_{d^{1}} e_{d^{1}}+k_{d^{2}} e_{d^{2}} & +\cdots \\
& +k_{d^{N}} e_{d^{N}}+k_{a^{N}} e_{a^{N}}
\end{aligned}
$$

where $e_{d^{1}}, \quad e_{d^{2}}, \ldots, e_{d^{N}}$ corresponds to detail components of the error signal and $e_{a^{N}}$ is the approximate component of the error signal. The gains $k_{d^{1}}, k_{d^{2}}, \ldots, k_{d^{N}}$ are used to tune the high and medium frequency components of the error signal. Gain $k_{a^{N}}$ is used for tuning the low frequency component of the error signal. These gain constants can be generated using intelligent techniques [10]. In the proposed work, self-tuning mamdani fuzzy inference engine is used to generate the gain constants, making the controller a hybrid one.

In the proposed controller, the level of decomposition of the error signal is obtained as two, using the entropy based criterion [24] as

$$
u_{w}=k_{d^{1}} e_{d^{1}}+k_{d^{2}} e_{d^{2}}+k_{a^{2}} e_{a^{2}}
$$

While dealing with motor drives, the command and disturbance are low frequency signals. The sensor noises are high frequency signals. Therefore the gain $k_{a^{2}}$ which corresponds to low frequency components of the error signal can be used to improve the disturbance rejection of the system. The gain $k_{d^{2}}$ which corresponds to medium frequency components of the error signal, which adds damping to the system can be used to improve the transient response. The gain $k_{d^{1}}$ which corresponds to high frequency components of the error signal can be set to zero to eliminate the effect of noise on the system. To get optimum results, the gain parameters can be obtained using self tuning fuzzy logic. Fig 3 shows the schematic of the hybrid wavelet fuzzy based self tuning MR controller for robust speed control of induction motor drives [25].

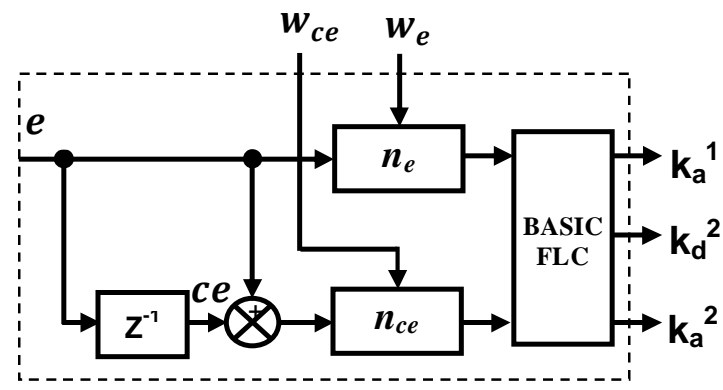

Fig. 4. Structure of Self-Tuning FLC Block

\section{Wavelet based Self-tuning MR Controller}

\subsection{Wavelet based Self-tuning}

The self tuning of fuzzy logic can be obtained by using a tuning algorithm to directly adjust any one of the following i) the fuzzy rules ii) the membership function iii) the scaling gains. But the highest priority in these was given to tune the scaling gains in the recent literature, due to the influence of the gains on the performance of the system. In the proposed work, the 
real time tuning of the scaling gains are performed to get the desired performance. The self tuning mechanism consists of a performance model, evaluation block and FLC block [15].

The reference model describes the dynamic performance of the drive. For an induction motor, the reference model can be approximated by a second order system (21). The second order model is obtained from the procedure used in [2] and the constants $a$ and $b$ are adjusted to meet the specific requirements of induction motor investigated in the proposed work.

$$
H_{I m}(s)=\frac{a}{s^{2}+b s+a}
$$

The rotor speed $\omega_{r}$ is compared with the output from the reference model $\omega_{r}^{\prime}$, to generate the speed error $e_{r}^{\prime}$. This error signal is given as input to the evaluation block. The evaluation block is designed such that, if the error signal is within $\pm 1 \mathrm{rad} / \mathrm{sec}$, the self tuning mechanism will not operate. If the error $e_{r}^{\prime}$ exceeds the specific range of $\pm 1 \mathrm{rad} / \mathrm{sec}$, the evaluation block generates the tuning error $e_{\omega}$ to be given as input to TS FLC block. The FLC operates on this error signal to generate the online weight values $w_{e}$ and $w_{c e}$. These weight values are used to generate the scaling gains $n_{e}(k)$ and $n_{c e}(k)$ of the self tuning FLC. The scaling constants of the self-tuning FLS are generated at each step as

$$
\begin{aligned}
n_{e}(k) & =n_{e}(k-1)\left[\alpha w_{e}(k)\right] \\
n_{c e}(k) & =n_{c e}(k-1)\left[\beta w_{c e}(k)\right]
\end{aligned}
$$

where $\alpha$ and $\beta$ are weight constants. The self tuning FLC operates on these scaling gains and the actual error $e$, to generate the gains $k_{d^{1}}, k_{d^{2}}$ and $k_{a^{2}}$, which are used to tune the high, medium and low frequency components of the error signal $e_{d^{1}}, e_{d^{2}}$ and $e_{a^{2}}$ respectively.

\subsection{Self-tuning Fuzzy Logic}

Figure 4 shows the structure of self-tuning FLC block. The inputs are error (e) and change in error (ce). $w_{e}$ and $w_{c e}$ are the scaling gains obtained from the TS-FLC block. These gains will be varied online to tune the FLC block [25].
Table I. Fuzzy Rule Matrix

\begin{tabular}{cccccc}
\hline e & NB & NM & ZE & PM & PB \\
\hline NB & NB & NB & NB & NM & ZE \\
NM & NB & NB & NM & ZE & PM \\
ZE & NB & NM & ZE & PM & PB \\
PM & NM & ZE & PM & PB & PB \\
PB & ZE & PM & PB & PB & PB \\
\hline
\end{tabular}

The basic FLC block consists of fuzzy interface, fuzzy rules, fuzzy inference and defuzzification interface. The input and output variables are fuzzified using five membership functions normalised between +1 and -1 . The range of input and output variables can be changed by altering the scaling gains $n_{e}$ and $n_{c e}$ - Centroid method of defuzzification is used to compute the outputs.

The scaling gains are also generated in a similar way, with five membership functions and 25 rules, using the TS-FLC block. In the design of the rule base, the look up table is created offline, using the simulation data obtained during load torque disturbances and sudden changes in the set speed. The fuzzy look up table is given in Table I. The scaling gains will be generated only when the error $e_{r}^{\prime}$ is greater than $+1 \mathrm{rad} / \mathrm{sec}$. Moreover, the tuning is performed according to a simple predefined performance indicator. The integral of the time multiplied by the absolute value of the error (ITAE) criterion is used (24) to locally optimize the controller and evaluate the degree in which the current set parameters satisfy the formulated objective.

$$
S_{\text {ITAE }}=\int_{0}^{t_{\max }} t \cdot\left|e_{w}(t)\right| \cdot d t
$$

If the speed error $\mathrm{e}_{\mathrm{w}}^{\prime}$ in not within the specified limit, the TS-FLC block operates as follows [22]

$$
\begin{gathered}
\text { If }\left\{\mathrm{e}_{\mathrm{r}} \text { is ZERO and } \mathrm{ee}_{\mathrm{r}} \text { is ZERO }\right\} \\
\text { THEN }\left\{\omega_{\mathrm{e}} \text { is ZERO and } \omega_{\text {ce }} \text { is ZERO }\right\}
\end{gathered}
$$

The $\mathrm{n}_{\mathrm{e}}$ and $\mathrm{n}_{\mathrm{ce}}$ values are calculated from $\omega_{e}$ and $\omega_{c e}$ using (22) and (23). This self tuning mechanism optimises the proposed wavelet-fuzzy self tuning MR controller to ensure robustness. 


\section{Control Algorithm}

The flow chat for implementing the proposed control algorithm is shown in Fig. 6. The first step of the design is to generate the speed error for different conditions and disturbances using a PI controller. The speed error is used to select the optimum wavelet function and the level of decomposition. The wavelet parameters can be now initialized using the selected wavelet function and the level of decomposition. The level of decomposition can still be increased which results in improved performance. However the complexity of the controller still goes high since the number of scaling gains required increases with the increase in level of decomposition.

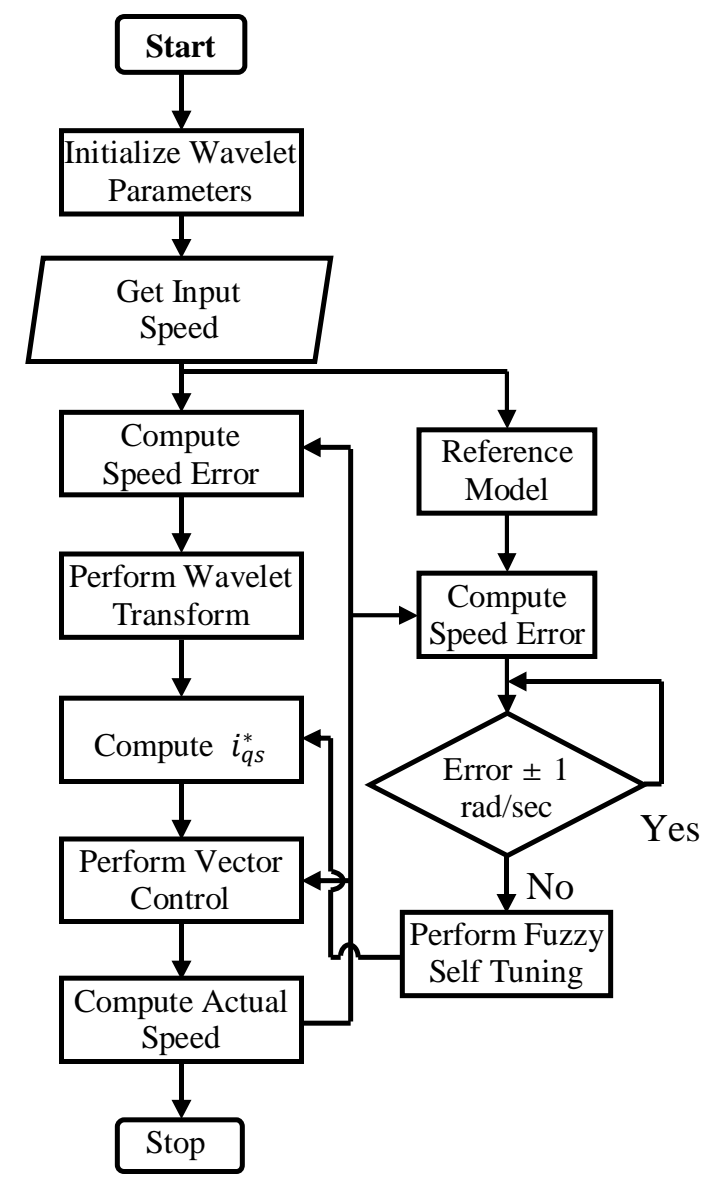

Fig. 6. Flowchart of the proposed wavelet-fuzzy control algorithm for Induction motor drives
The initial values of the scaling gains can be fixed by trail and error method and the speed controller is simulated under different conditions. The lookup table for the fuzzy logic block is constructed offline during simulations using the load torque disturbances, sudden changes in command speed, change in moment of inertia and change in stator resistance. The error speed and the change in error speed data are collected and is used for generating the look up table. The control output of the IFOC scheme is computed using equation (20). The fuzzy based self tuning scheme generates the optimum scaling gains for the proposed controller and the scaling constants are updated on line using the self tuning algorithm.

The command speed is also given as input to the reference model. The actual rotor speed and the reference speed from the reference model are compared and are used to decide the working of the self-tuning algorithm. The self tuning algorithm works only if the error speed is more than $\pm 1 \mathrm{rad} / \mathrm{sec}$. If the speed error is more than $\pm 1 \mathrm{rad} / \mathrm{sec}$, the self tuning algorithm will be activated by the evaluation block and the speed error between the actual speed and the reference model speed is given as the input to TS - FLC block. The TS-FLC operates on the error signal to generate the weight values of the self-tuning fuzzy logic. The scaling constants of the self-tuning FLC are updated using the weight values generated by the TS-FLC on line using (22) and (23) .

The error speed is given as input to the proposed wavelet-fuzzy based MR controller. The error speed is decomposed in to different frequency components using wavelet transform. The wavelet coefficients along with the gain constants obtained from Self-tuning FLC are use to generate the torque producing current component for IFOC of induction motor. The torque component current $i_{q s}^{*}$ is used to generate the switching pulses for the inverter using SVPWM technique. The IGBTs based inverter drives the induction motor. 


\section{Simulation Results}

The effectiveness of the proposed wavelet-fuzzy based self tuning MR controller is validated by simulation results under different operating conditions and load disturbances. Simulations are performed using MATLAB/Simulink on a $5 \mathrm{hp}$ induction motor. The sampling time of simulation is fixed as $200 \mathrm{msec}$.

The IFOC of induction motor is also simulated with conventional fixed gain PI controller and fuzzy-PI controller to compare the effectiveness of the proposed controller. The gain values of the PI controller are fixed using Ziegler and Nichols method [18] in order to get smooth response. The fuzzy-PI controller is simulated using [2], [7].
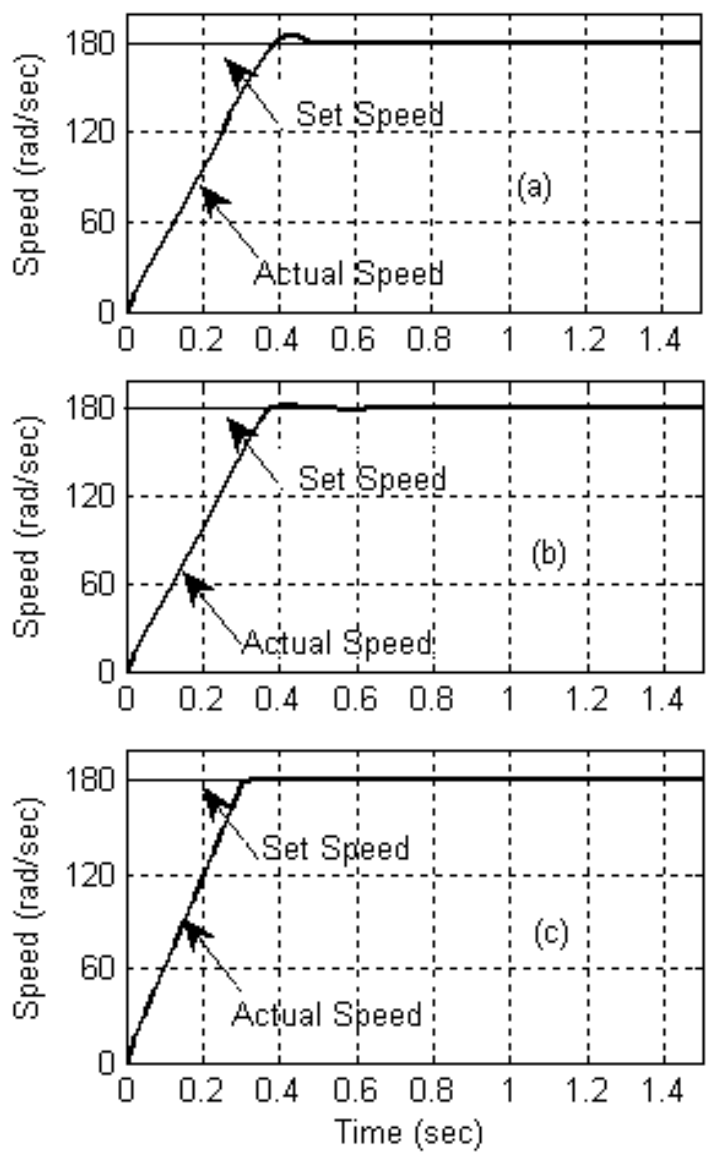

Fig. 7. Simulated starting response for a set speed of 180 $\mathrm{rad} / \mathrm{sec}$ (a) PI controller (b) Fuzzy-PI controller (c) Proposed Wavelet-Fuzzy Controller.
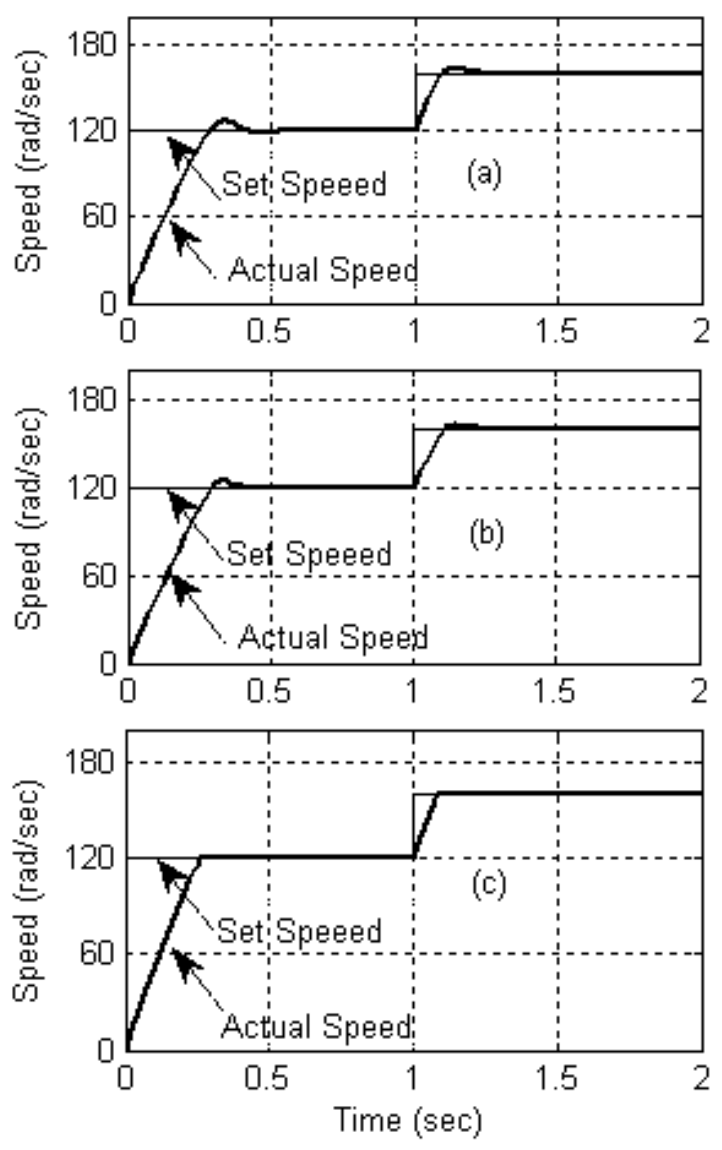

Fig. 8. Simulated response for a step chance in set speed from $120 \mathrm{rad} / \mathrm{sec}$ to $160 \mathrm{rad} / \mathrm{sec}$ (a) PI controller (b) Fuzzy-PI controller (c) Proposed Wavelet-Fuzzy Controller.

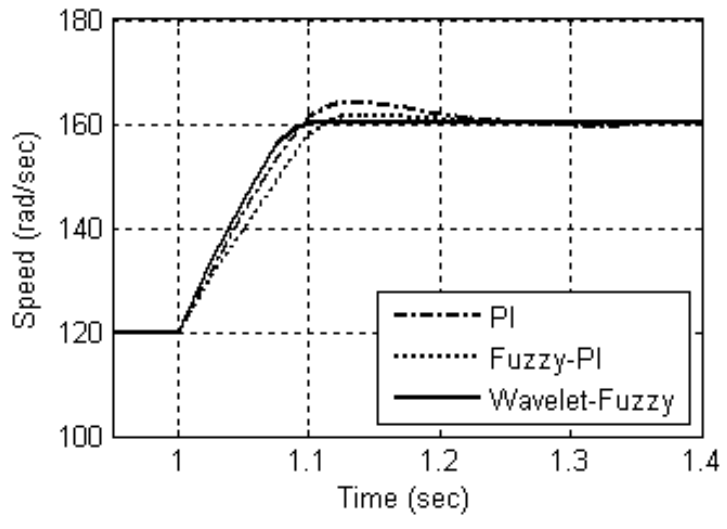

Fig. 9. Comparision of the step change in set speed for PI controller, Fuzzy-PI controller and the Proposed WaveletFuzzy Controller. 

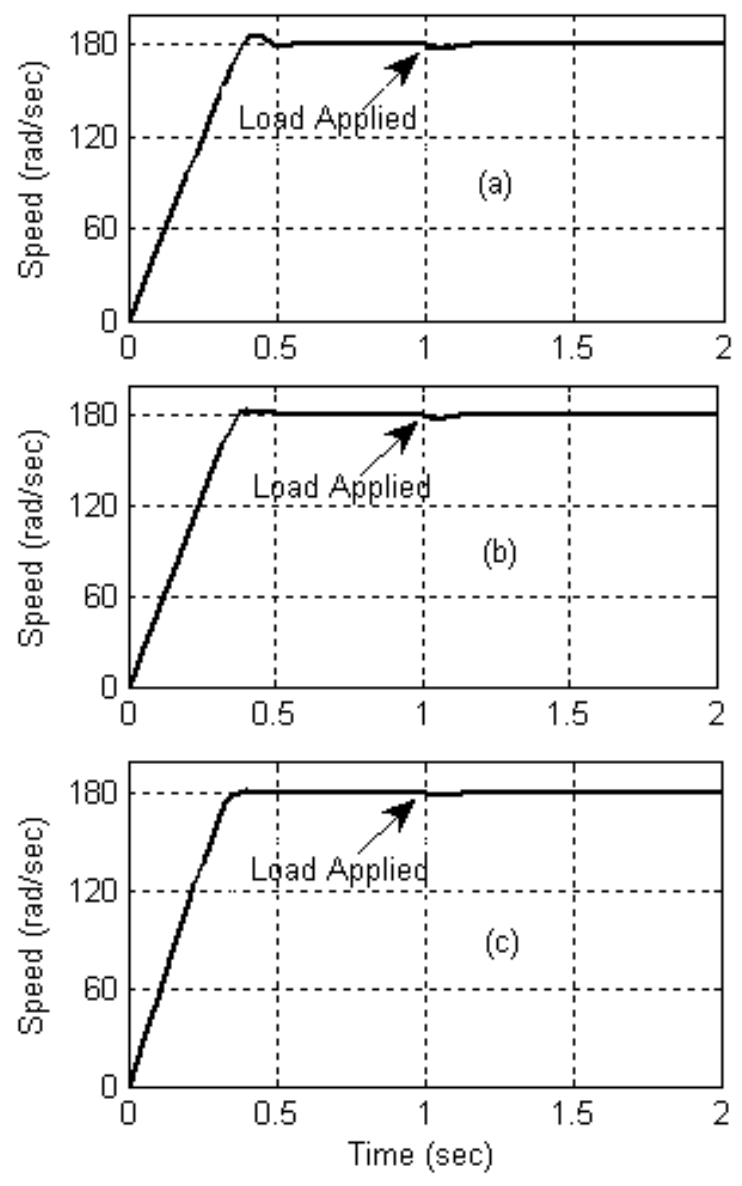

Fig. 10. Simulated response for a step chance in load at $\mathrm{t}=$ 1sec (a) PI controller (b) Fuzzy-PI controller (c) Proposed Wavelet-Fuzzy Controller.

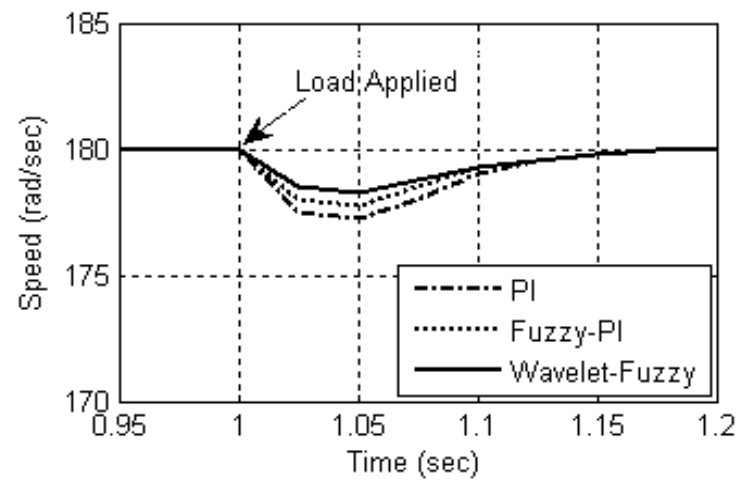

Fig. 11. Comparision of the speed response for a step change in load for PI controller, Fuzzy-PI controller and the Proposed Wavelet-Fuzzy Controller.
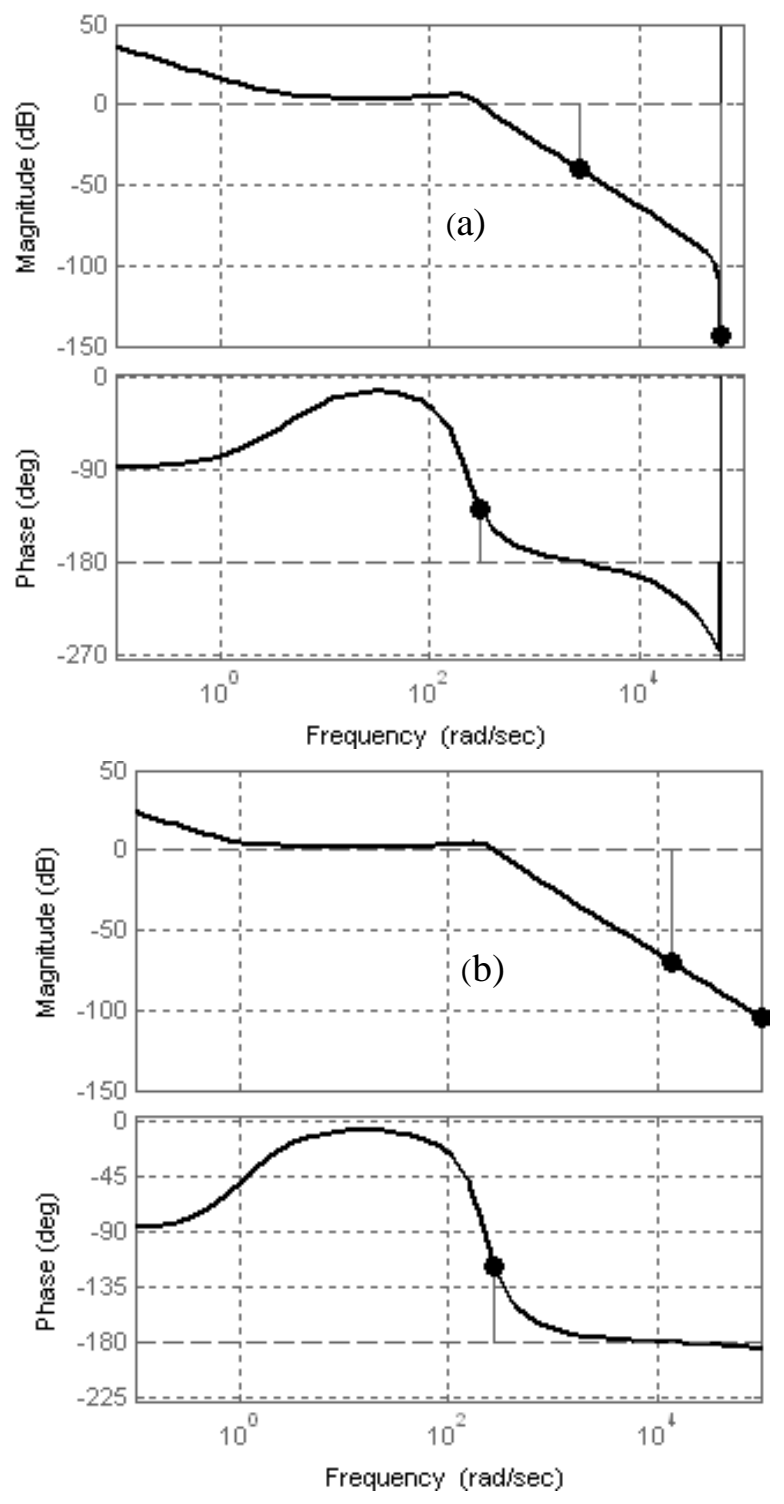

Fig. 12. Magnitude and phase response of the system for the (a) PI Controller and (b) proposed wavelet fuzzy Controller.

Fig. 7. (a)-(c) shows the speed response of the induction motor started at no load with a set speed of $180 \mathrm{rad} / \mathrm{sec}$.. It is clearly seen that the response of the wavelet-fuzzy based self tuning MR controller outperforms conventional PI and fuzzy-PI controllers. The response of the speed control system to a step change in set speed from $120 \mathrm{rad} / \mathrm{sec}$ to $160 \mathrm{rad} / \mathrm{sec}$ is investigated in Fig. 8. (a) - (c) for PI, fuzzy-PI and the 
proposed wavelet-fuzzy controller. Comparison of the responses is shown in Fig 9. Comparing the performances, the proposed MR controller shows significant improvement in settling time. It is able to follow the set speed without overshoot and steady state error.

Fig.10. (a)-(c) shows the simulated speed response when a sudden load is applied for PI, fuzzy-PI and the proposed wavelet-fuzzy controller. Comparison of the responses is shown in Fig 11. A step increase in load is applied at $\mathrm{t}=1.0 \mathrm{sec}$. It is observed that the proposed wavelet-fuzzy based MR controller gives better results when compared with the conventional PI and fuzzy-PI controllers.

The closeness between set speed and actual speed is quantified by the root mean square error (RMSE). The RMSE results are summarized in Table II. The RMSE results show that the proposed wavelet-fuzzy based MR controller has reduced RMSE under different operating conditions compared to conventional PI and fuzzy PI controllers.

Table II. The RMSE results

\begin{tabular}{cccc}
\hline $\begin{array}{c}\text { Change in } \\
\text { Speed } \\
\text { (rad/sec) }\end{array}$ & PI & Fuzzy & Proposed \\
\hline 0 to 180 & 51.85 & 50.26 & 49.82 \\
120 to 90 & 28.38 & 27.04 & 26.56 \\
120 to160 & 28.70 & 27.24 & 26.84 \\
\hline
\end{tabular}

The frequency domain performance of the proposed controller as well as conventional PI controller is analyzed using bode plot. The magnitude and the phase plot is shown in Fig. 12. (a) and (b) for the PI controller and the proposed wavelet fuzzy based MR controller. Analyzing the frequency response curves of the controllers, it can be concluded that the proposed wavelet-fuzzy based MR controller is having better gain margin and phase margin compared to the conventional PI controller. The comparison of the frequency domain parameters are shown in Table III.

Table III. Frequency domain Parameters

\begin{tabular}{ccc}
\hline Controller & Gain Margin & Phase Margin \\
\hline PI & $42.62 \mathrm{~dB}$ & $51.73 \mathrm{rad} / \mathrm{sec}$ \\
Proposed & $64.9 \mathrm{~dB}$ & $60.14 \mathrm{rad} / \mathrm{sec}$ \\
\hline
\end{tabular}

\section{Experimental Results}

The block diagram for the real time implementation of the proposed wavelet-fuzzy based controller is shown in Fig. 13. It mainly consists of an induction motor, control PC, digital signal processor (DSP) board, IGBT based SVPWM inverter and measuring instruments. The

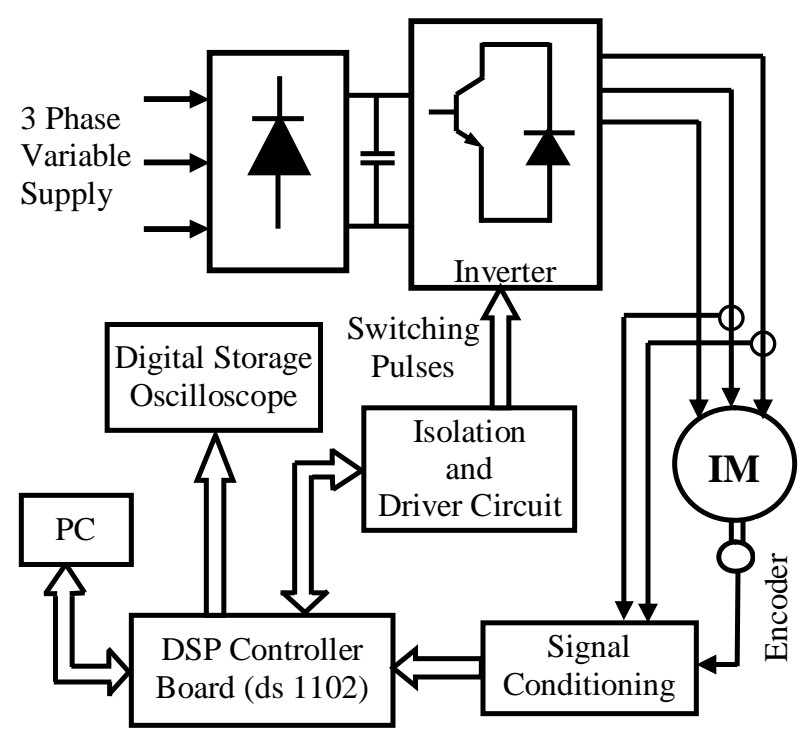

Fig. 13. Block diagram of the real-time implementation of the proposd wavelet-fuzzy based controller

induction motor is of $5 \mathrm{hp}$ rating. The motor nominal parameters are summarized in Table IV.

The proposed self-tuning MR wavelet fuzzy controller has been implemented in the dSPACE ds1102 DSP controller in real time. The main processor of the DSP board is the 32 bit floating bit digital processor TMS 320C31. The DSP board consists of all the required peripherals such as analog to digital (A/D) converter, digital to analog (D/A) converter and incremental encoder interfaces. The dSPACE control desk software has been used to download the proposed control algorithm in the DSP board. The control desk soft ware is also used to give the set speed command to the motor. The motor currents were measured using the hall-effect sensors. The actual speed of the motor is computed from the encoders connected to the motor. These signals were given as input to the DSP board through the A/D converter after proper signal conditioning. The proposed wavelet-fuzzy based speed controller is used to generate 
are fed through the isolation and driving circuit, to trigger the IGBT's of the three-phase inverter. Digital storage oscilloscope with a bandwidth of $100 \mathrm{MHZ}$ and real time sampling rate of 500 mega samples per second(MS/s) is used for tracing the speed responses.

Several tests were performed on the laboratory setup to evaluate the performance of the proposed hybrid wavelet fuzzy based controller.

There will be no extra cost incurred for the hardware set up since the same hardware required for the fuzzy based IFOC scheme can be used for the wavelet fuzzy based MR controller. However, due to the advancements in the processor technology and with the availability of DSP control board at low price, the cost of the proposed control scheme is cheaper when the torque command for the drive system. The digital output of the DSP control board is used as switching pulses for the SVPWM inverter. These digital signals compared with field programmable gate array (FPGA) based control schemes for the same performance.

The control algorithm of the induction motor drive was also implemented with PI controller in order to compare the performance with the proposed controller. In order to make a fair judgment, the gain of the PI controller is adjusted using Ziegler and Nichols method [17]. The speed responses are observed at different operating conditions and load disturbances. The experimental starting response of the induction motor drive for a set speed of $180 \mathrm{rad} / \mathrm{sec}$ is shown in Fig. 14 (a) - (c) for the conventional PI controller, the fuzzy PI controller and the proposed wavelet fuzzy MR controller respectively. It can be observed that proposed wavelet fuzzy based MR controller gives better responses in terms of overshoot, steady-state error and settling time.

The experimental speed responses with a step change in speed from $120 \mathrm{rad} / \mathrm{sec}$ to $180 \mathrm{rad} / \mathrm{sec}$ are shown in Fig. 15 (a) - (c) for the conventional PI controller, the fuzzy PI controller and the proposed hybrid wavelet fuzzy controller respectively. It can be observer the proposed controller performs better for sudden change in set speed compared to conventional PI controller and fuzzy PI controller. The experimental response for a sudden change in load for is shown in Fig. 16 (a) - (c) for the conventional PI controller, the fuzzy PI controller and
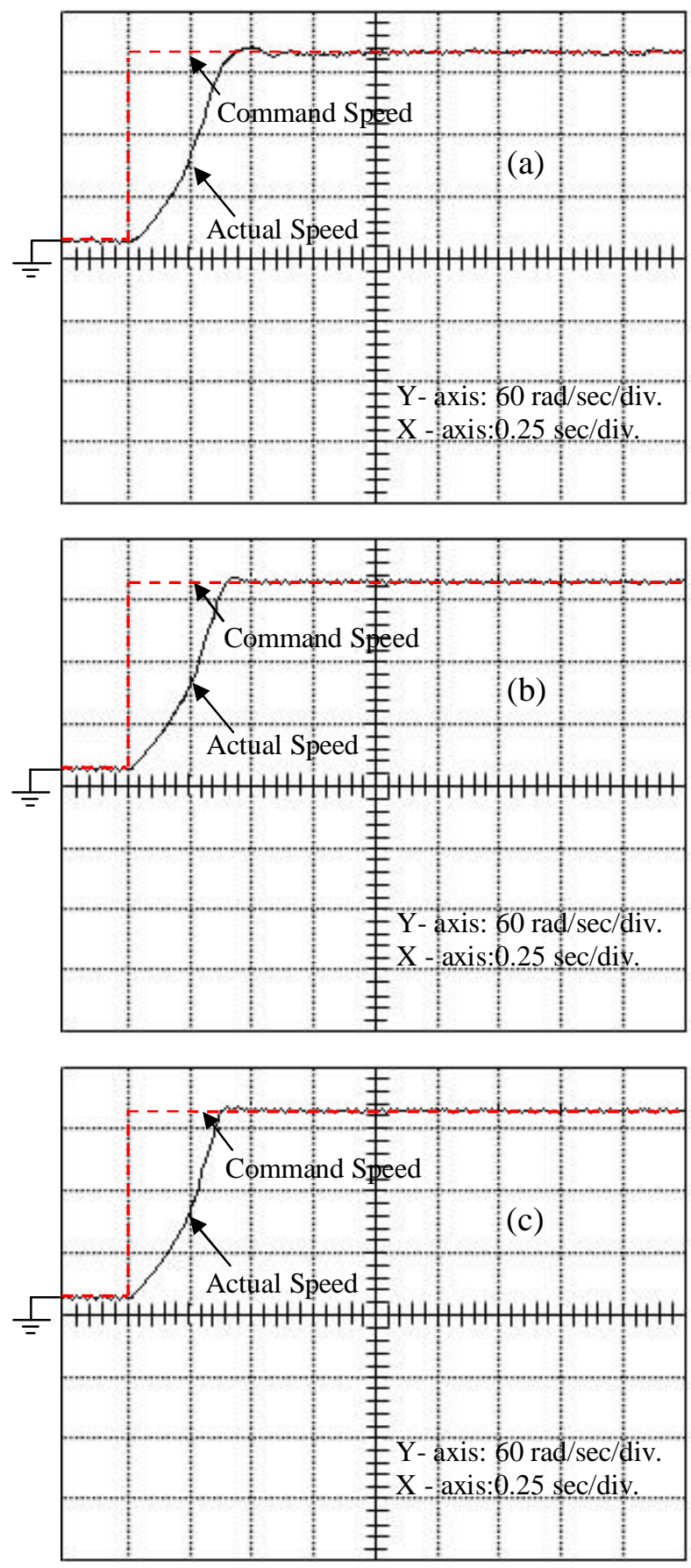

Fig. 14. Experimental results for starting performance of (a) PI controller (b) Fuzzy PI controller and (c) the proposed Wavelet fuzzy controller. 

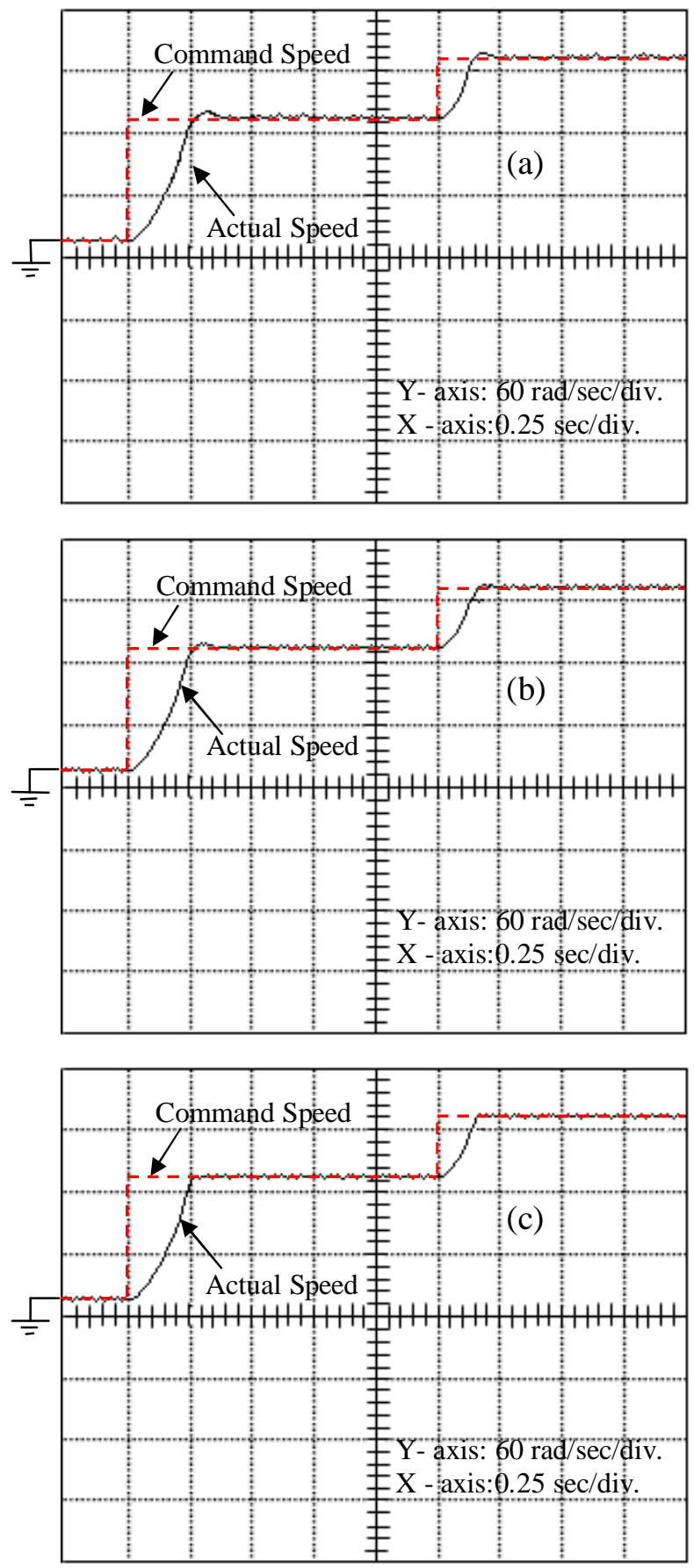

Fig. 15. Experimental results for step change in set speed for (a) PI controller (b) Fuzzy PI controller and (c) the proposed Wavelet -
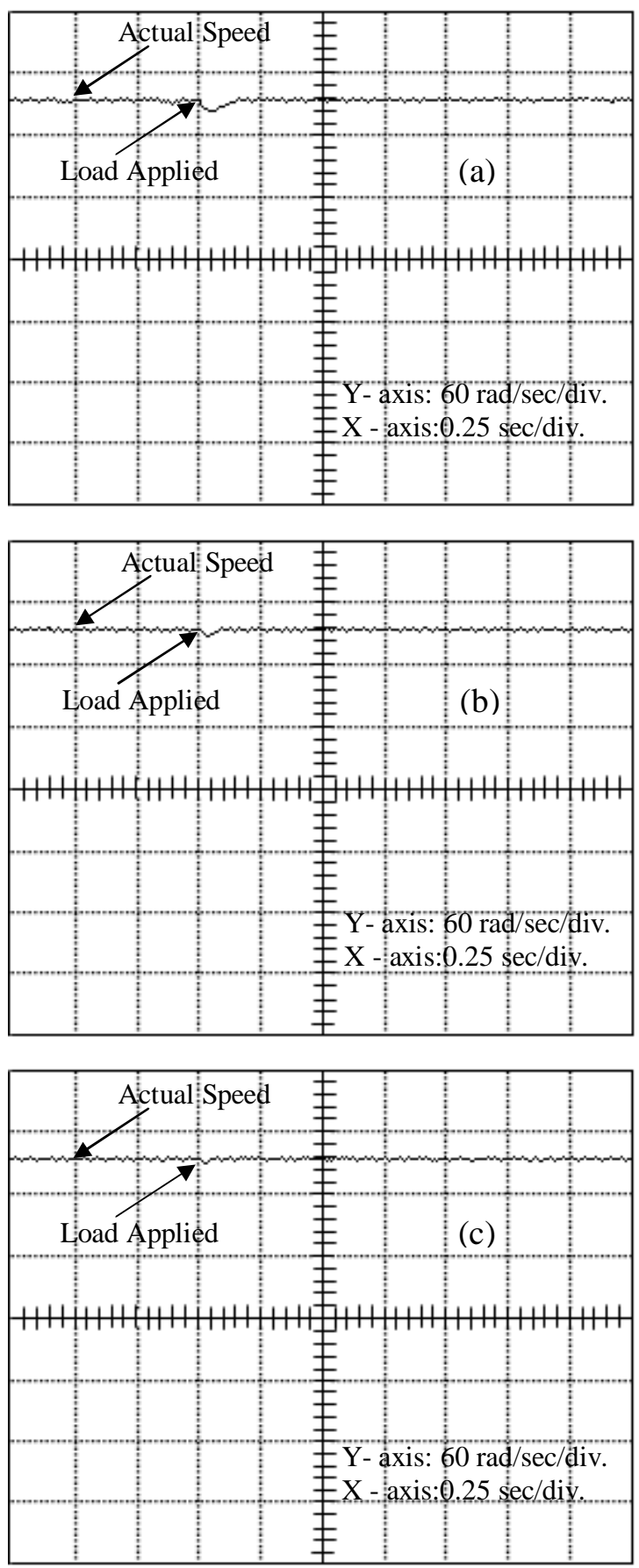

Fig. 16. Experimental results for sudden change in load for (a) PI controller b) Fuzzy PI controller and (c) the proposed Wavelet fuzzy controller 
the proposed wavelet fuzzy MR controller respectively. The proposed hybrid wavelet fuzzy MR controller has found to be insensitive to load disturbances compared to the conventional PI controller and fuzzy PI controller.

Table IV. Motor Nominal Parameters

\begin{tabular}{ll}
\hline Rated power [hp] & 5.0 \\
Rated voltage $[\mathrm{V}]$ & 460 \\
Rated frequency $[\mathrm{Hz}]$ & 60 \\
Rated speed [rpm] & 1750 \\
Number of pole pairs & 2 \\
Stator resistance $[\Omega]$ & 1.12 \\
Rotor resistance $[\Omega]$ & 1.08 \\
Stator Inductance $[\mathrm{mH}]$ & 5.97 \\
Rotor Inductance $[\mathrm{mH}]$ & 5.97 \\
Motor inertia $\left[\mathrm{kgm}^{2}\right]$ & 0.02 \\
Friction factor $[\mathrm{Nms}]$ & 0.005752 \\
\hline
\end{tabular}

\section{Conclusion}

In this paper a wavelet-fuzzy based self tuning MR controller has been designed, simulated and implemented for robust speed control of induction motor drive. DWT is used to decompose the error between the set speed and actual speed into different frequency components. A fuzzy logic based self tuning algorithm is used to compute the scaling gains of the wavelet based controller. The proposed hybrid waveletfuzzy based MR controller was validated using simulation and experimental results under different operating conditions and load disturbances. Experimental and simulation results prove that proposed wavelet-fuzzy based MR controller is more robust when compared to conventional PI and fuzzy-PI controllers, in terms of smaller overshoot, settling time, disturbance rejection and smooth control.

\section{References}

1. M. A. S. K. Khan and M. A. Rahman, Implementation of a new wavelet controller for interior permanent magnet motor drives, IEEE Trans. Ind. Appl. 44(6) (2008) 19571965.

2. L. Zhen and L.Xu, Fuzzy learning enhanced speed control of an indirect field-oriented induction machine drive, IEEE Trans. Control System Techn. 8(2) (2000) 270-278.
3. R.J.Wai and K.-H. Su, Adaptive enhanced fuzzy slidingmode controlfor electrical servo drives, IEEE Trans. Ind. Electron. 53(2) (2006) 569-580.

4. E. Cerruto, A. Consoli, A. Raciti, and A. Testa, Fuzzy adaptive vector control of induction motor drives, IEEE Trans. Power Electron., 12(6) (1997) 1028-1040.

5. R.J Wai and H.H. Chang, Backstepping neural network control for indirect field-oriented induction motor drive, IEEE Trans. Neural Netwk. 15(2) (2004) 367-382.

6. S. Parvez and Z. Gao, A wavelet-based multiresolution PID controller, IEEE Trans. Ind, Appl. 41(2) (2005) 537 $-543$.

7. M. N. Uddin, T. S. Radwan, and A. Rahman, Performances of fuzzy logic-based indirect vector control for induction motor drive, IEEE Trans. Ind. Appl. 38(5) (2002) 1219-1225.

8. C. M. Liaw and F. J. Lin, Position control with fuzzy adaptation for induction servomotor drive, Proc. IEE Electric Power Appl. 142(6) (1995) pp. 397-404.

9. L. Mokrani and R. Abdessemed, A fuzzy self-tuning PI controller for speed control of induction motor drive, Proc. IEEE Conf. Control Appl. (2003) 785-790.

10. M. A. S. K. Khan and M. A. Rahman, A Novel neuro wavelet based self-tuned wavelet controller for IPM motor drives, IEEE Trans. Ind. Appl. 46(3) (2010) 1194 1203.

11. R. J. Wai and J. M. Chang, Intelligent control of induction servo motor drive via wavelet neural network, Electric Power Systems Research, 61(1) (2000) 67 - 76.

12. L.K Wong, F.H.F Leung and P.K.S Tam, A fuzzy sliding controller for nonlinear systems, IEEE Trans. Ind.Electron. 48(1) (2001) 32-37.

13. K.K. Shyu and H.J. Shieh, Variable structure current control for induction motor drives by space voltage vector PWM, IEEE Trans. Ind. Electron. 42(6) (1995) 572-578.

14. M. Azadi, A. Rahideh, A. A. Safavi, and O. Mahdiyar, Wavenet based vector control of a Permanent Magnet Synchronous Motor Drive, Proc. IEEE EMDC, Antalya (2007) 1663-1668.

15. L. Liu, S. Shen, S. Liu, Q. Liu, and W. Liao, Stator resistance identification of induction motor in DTC system based on wavelet network, Proc. 6th World Congr. Intell. Control Autom. (2006) 6411-6415.

16. Y. Miloud, A. Miloudi, M. Mostefai, and A. Draou, Selftuning fuzzy logic speed controller for inductionmotor drives, Proc. IEEE Int. Conf. Ind. Technol. (2004) 454459.

17. N. B. Nichols and J. G. Ziegler, Optimal settings for automatic controllers, J. of Dyn. Syst. Meas. Cont. 115(2B) (1993) 220-222.

18. Hasan A. Yousef, Mohamed E. Elkhatib and Omar A. Sebakhy, Wavelet network-based motion control of DC motors, Expert Systems with App.: An Int. J. 37(2) (2010) 1522-1527. 
19. E. Cerruto, A. Consoli, A. Raciti and A. Testa, Fuzzy adaptive vector control of induction motor drives, IEEE Trans. power Electron. 12(6) (1997) 1028 -1040.

20. F. J. Lin and R. J. Wai, Adaptive fuzzy neural network control for IM spindle motor drive, IEEE Trans. Energy Conv. 17(4) (2002) 507-513.

21. Y. Li, L. Zhang, D. Guo and Y. Shi, Implementation of SRM principle based on wavelet multi-resolution approximation, Proc. Int. conf. Mechtronics and Autom. (2007) 844-849.

22. M. Masiala, B. Vafakhah, J. Salmon and A. M. Knight Fuzzy self-tuning speed control of an indirect fieldoriented control induction motor drive, IEEE Trans. Ind. Appl 44(4) (2008) 1732-1740.

23. E. Y. Hamid and Z. I. Kawasaki, Wavelet based data compression of power system disturbances using the minimum description length criterion, IEEE Trans. Power Del. 17(2) (2002) 460-466.

24. S. G. Mallat, A theory of Multi-resolution Signal Decomposition: The Wavelet Representation, IEEE Trans. Pattern Anal. Mach. Intell. 11(7) (1989) 674-693.

25. J. L. F. Daya and V. Subbiah, A novel wavelet-fuzzy based controller for robust speed control of induction motor drives, Australian J. of Electrical and Electronics Engineering 9(2) (2012) 185-195.

26. Matlab/Simulink User Guide, (The MathWorks, Inc., Natick, MA, 1997).

27. B.K Bose, Modern power Electronics and AC Drives, (Pearson Education, 2002). 